\title{
Depth gradient on the resource use of a fish community from a semi-enclosed sea
}

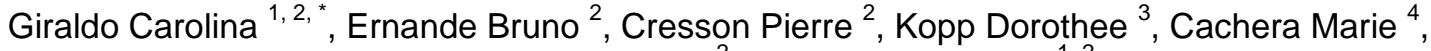 \\ Travers-Trolet Morgane ${ }^{2}$, Lefebvre Sebastien ${ }^{1,2}$
}

${ }^{1}$ Univ Lille 1, CNRS, ULCO LOG Lab Oceanol \& Geosci UMR8187, Wimereux, France.

2 IFREMER, Lab Ressources Halieut, Boulogne Sur Mer, France.

${ }^{3}$ IFREMER, Unite Sci \& Technol Halieut, Lab Technol \& Biol Halieut, Lorient, France.

${ }^{4}$ UBO, IUEM, UMR CNRS 6539, LEMAR, Technopole Brest Iroise, Plouzane, France.

* Corresponding author : Carolina Giraldo, email address : Carolina.Giraldo@ifremer.fr

\begin{abstract}
:
Depth is one of the environmental variables influencing the structure of marine food webs by directly or indirectly influencing benthic-pelagic coupling and predator-prey relationships. In shallow waters, the high degree of connectivity between pelagic and benthic networks results in complex systems with multiple interactions. Digestive tract (DT) and stable isotope (SI) analyses were used to investigate depth-related changes in feeding patterns for 33 fish species (eastern English Channel [EEC]) collected between $5 \mathrm{~m}$ and $80 \mathrm{~m}$ depth. Fish species were first arranged into functional groups based upon trophic and habitat similarities. DTs were used to determine the general topology of the food web and Sls were used to estimate the contributions of different sources to fish diets. At the scale of the aggregated EEC food web, the main food sources for all groups were of benthic origin (>50\%). The aggregated food web was then used as a template to explore the influence of depth on resource use by predatory fish. Mixing models including depth as a continuous covariate successfully untangled and identified different feeding strategies among functional groups. In shallow waters, fish species benefited from both pelagic and benthic prey whereas, in deeper waters, they fed predominantly on either benthic or pelagic sources depending on their habitat preferences. Our results support the hypothesis of a stronger benthic-pelagic coupling in shallow waters, notably through fish diet, and highlight the importance of including environmental factors such as depth as proxies of habitat variation to fully understand resource use and food web structure in epicontinental seas.
\end{abstract}




\section{Introduction}

Scientists have long recognized the importance of food web structure and functioning

39 to understand and predict the response of marine ecosystems to environmental change

40 (Woodward et al. 2010). The biotic compartment of marine ecosystems and its trophodynamics

41 respond to variability in the abiotic environment from the individual to the community level

42 (Keyl and Wolff 2008). Consequently, studying how food webs vary along natural gradients

43 from local to regional scales has been recognized as one of the fruitful avenues for future

44 research (Ings et al. 2009). Such environmentally-induced variability can be particularly

45 significant in semi-enclosed shallow seas that present low inertia to global (e.g., climate 
change) and/or local variations (e.g., river systems, fisheries) (Mackenzie et al. 2007, Martin et

47 al. 2010). As a result, numerous epi-continental seas (e.g., Baltic Sea, North Sea) are highly

48 dynamic and productive areas fueled by a large number of sources (e.g., freshwater inputs,

49 marine organic matter), characterized by a large number of species and biological interactions,

50 and where commercially important fish are caught every year.

51 Transfer of energy or matter between benthic and pelagic compartments can be

52 described as a two-way process accounting for the amount of pelagic material that reaches the

53 sea floor (pelagic-benthic coupling) but also for the amount of benthic organic matter that is

54 available and consumed by pelagic species (benthic-pelagic coupling; Gaudron et al. 2016).

55 Studies on pelagic-benthic coupling in polar and temperate regions have successfully identified

56 a close relationship between primary production in the water column and benthic biomass or

57 abundance (Grebmeier 1993, Cresson et al. 2014b). Similarly, deep (> $500 \mathrm{~m}$ ) benthic trophic

58 webs are largely dependent upon sinking organic matter of pelagic origin (Iken et al. 2001,

59 Cresson et al. 2014a). However, few studies have documented and recognized the importance

60 of benthic production to the whole food web in semi-enclosed shallow marine ecosystems

61 where its contribution is expected to be high due to the proximity between pelagic and benthic

62 species and the virtual absence of physical barriers such as thermoclines. Among the factors

63 influencing benthic-pelagic coupling (e.g., vertical current, primary production, nyctemeral

64 migrations, community composition), depth is one of the main forcing variables (Woodland

65 and Secor 2013) that can be easily measured and is usually available for all studies. Depth is

66 directly or indirectly related to different physical (e.g., water mixing, sinking time of organic

67 matter) and biological processes (e.g., vertical migration of species) (Baustian et al. 2014) and

68 can be used as a proxy of habitat variation to explore benthic-pelagic coupling and its impact

69 on aquatic food webs'structure (Kopp et al. 2015). 
Energetic links can be studied using fish as integrators of benthic-pelagic coupling (and

71 the other way round pelagic-benthic coupling) by exploring fish trophic interactions and their

72 variation with depth (Romero-Romero et al. 2016). At the community level, fish are

73 characterized by a remarkable diversity of feeding strategies, life-history traits and associated

74 morphologies that are expected to respond differently to environmental variability. Flatfishes

75 (e.g., European plaice), generally characterized as endobenthos-feeders, spend most of their

76 time on the bottom and, for the majority, do not feed by sight (Gibson et al. 2014). Due to the

77 characteristics of such sedentary species, such as swimming short distances and creating

78 moderate disturbances of the bottom to forage (Link et al. 2002), we expect their diet to

79 originate from benthos regardless of depth. Benthic round fish (e.g., Gadoids) share a relatively

80 similar diet with endobenthos-feeders (mainly benthic prey). However, differences in their

81 morphological traits and feeding modes (visual predation) should allow them to take greater

82 advantage of available pelagic prey (e.g., copepods) when moving from deep to shallow

83 feeding grounds (Jönsson et al. 2013). Small forage fish (e.g., sprat, herring) are generally

84 identified as omnivorous pelagic planktivores (Mollmann et al. 2004). Yet, studies show that

85 larger specimens of some species (e.g., herring) can also be nectobenthos-feeders preying on

86 small benthic crustaceans and polychaete worms (Casini et al. 2004). Although the main food

87 sources of this functional group are expected to be of pelagic origin, benthic-derived material

88 may also play a significant role in its diet in shallow environments. Finally, piscivorous round

89 fish (e.g., European seabass) form a broad group that can occupy different habitats (pelagic or

90 demersal) and are among the largest specimens within the fish community. Although they

91 preferentially feed on fish (Juanes et al. 2002) thus occupying higher trophic levels, most

92 piscivores are opportunistic and have flexible diets. Piscivorous round fish are thus likely to

93 consume the most abundant food source regardless of its origin (Post et al. 2000). 
In this study, we used data from the eastern English Channel (EEC), a semi-enclosed

95 sea, as a case study to address the following objectives: 1) identify the main trophic

96 interactions and describe the resulting food web structure at the EEC-scale; 2) explore variation

97 in fish resource partitioning with depth; and 3) compare the general structure of trophic

98 interactions within the fish community at the EEC-scale with other shallow semi-enclosed

99 systems. Based on a previous study (Kopp et al. 2015) and common knowledge on species'

100 habitat use and feeding strategy, we hypothesize that benthic-pelagic and pelagic-benthic

101 coupling vary with depth as the latter influences fish diets: pelagic-feeding species benefit from

102 benthic subsidies in shallow waters and the contribution of pelagic sources to their diet

103 increases with increasing depth as the benthic-pelagic coupling weakens; similarly, benthic-

104 feeding species benefit from pelagic subsidies in shallow waters and the contribution of benthic

105 sources to their diets increases with increasing depth as pelagic-benthic coupling weakens.

106 Diet estimates originating from digestive tract (DT) analysis and stable isotope (SI)

107 analysis provide a snapshot of the current prey sources and integrated information about food

108 resource use over several weeks to months, respectively. DTs of the main fish species (in terms

109 of commercial interest and/or ecological dominance) of the EEC have been reported by

110 Cachera et al. (2017) who studied sources of fish trophic niche variation at the individual level.

111 Additionally, SIs from the different compartments of EEC food web, including the main fish

112 species, were reported by Kopp et al. (2015) who showed an inshore-offshore gradient in the

113 food web structure and concluded that this gradient was related to a weakening of benthic-

114 pelagic and pelagic-benthic couplings towards offshore waters. To further understand the

115 processes underlying this phenomenon, we combined data from DTs and SIs within a Bayesian

116 framework, including depth as an environmental variable (Francis et al. 2011, Semmens et al.

117 2015). Species of the EEC food web were grouped into functional groups and DTs were used 
118 to define the general topology of the food web whereas SIs were used to calculate proportions

119 of the different prey in the diet of the various functional groups. Lastly, for fish functional 120 groups, variation of diet (based on DTs and SIs) along a depth gradient from 7 to $80 \mathrm{~m}$ was

121 explored.

122 Materials and Methods

123 Data

124 DT and SI data for fish and the majority of the epifaunal invertebrates $(n=799$ 125 samples) were collected using a GOV bottom trawl from R. V. "Gwen Drez" during the 126 Channel Ground Fish Survey (October 2009) that covers the whole EEC annually according to 127 a spatially stratified sampling scheme (Le Roy 2009). Additional SI data for zooplankton $(n=$ 128 16) and for benthic suspension feeders $(n=34)$ were respectively collected in January 2010 129 with a WP2 zooplankton net (International Bottom Trawl Survey; Vérin 2010) and in July 1302010 using a French dredge (COMOR survey; Foucher and Quinquis 2010). Finally, 131 particulate organic matter was obtained from water samples collected with Niskin bottles 132 during the French sampling program SOMLIT (October 2009 to June 2010). More details 133 about sampling protocols can be found in Kopp et al. (2015), Cachera et al. (2017) and 134 supplementary tables S1 and S2.

135 DT data were obtained by identifying prey to the lowest possible taxon in 853 digestive 136 tracts extracted from 16 fish species chosen to represent the main trophic guilds of the EEC 137 fish community (Chelidonichthys cuculus, Chelidonichthys lucerna, Clupea harengus, 138 Dicentrarchus labrax, Gadus morhua, Merlangius merlangus, Mullus surmuletus, Mustelus 139 asterias, Pleuronectes platessa, Raja clavata, Sardina pilchardus, Scomber scombrus 140 Scyliorhinus canicula, Solea solea, Sprattus sprattus, Trachurus trachurus; for more details on 141 digestive tract analysis see Cachera et al. 2017). 
Nitrogen and carbon SI ratios, denoted by $\delta^{15} \mathrm{~N}$ and $\delta^{13} \mathrm{C}$, respectively, were measured

143 from particulate organic matter, to zooplankton, epifaunal invertebrates, and fish collected

144 from 7 to $80 \mathrm{~m}$ depth in the EEC. A biplot of the SIs for each fish species arranged in functional

145 groups can be found in Supplementary Figure S1. Specific details on tissue samples analyzed

146 for SI ratios and their preparation can be found in Kopp et al (2015). Briefly, SI data were

147 normalized to account for lipid content based on $\mathrm{C}: \mathrm{N}$ ratios (Post et al. 2007) and corrected for

148 spatial variation in the isotopic baseline based on SI values of the suspension-feeding bivalve,

149 Aequipecten opercularis, taken as the baseline. SI values of the isotopic baseline at sampling

150 sites were obtained by kriging interpolation of published data (Jennings and Warr 2003a, b;

151 Barnes et al. 2009). For both nitrogen and carbon, the isotopic value of each consumer sample

152 was then corrected by subtracting the kriged baseline value at the sampling location and adding

153 the mean kriged baseline value averaged across the entire area (for all sampling sites:

$154 \delta[$ corrected $]=\delta[$ consumer $]-\delta[$ local baseline $]+\delta[$ mean baseline $]$ with $\delta$ the nitrogen $\delta^{15} \mathrm{~N}$ or 155 carbon $\delta^{13} \mathrm{C}$ SI ratio). Any further mentioning of SI data in this paper refers to baseline156 corrected SI values.

157 Food web modeling

158 The topological food web of the EEC was constructed by aggregating qualitatively the 15954 species sampled for SI into functional groups based on their taxonomic classification (e.g. 160 fish, cephalopods, bivalves), feeding strategies (e.g., filter feeders, scavengers), trophic guild

161 (e.g., herbivores, piscivores), habitat use (e.g., pelagic, demersal) and morphology (only for 162 fish, i.e., flatfish, round fish) using DT data reported by Cachera et al. (2017) for the main fish 163 species and completed by published data (see Supplementary Table 1 and 2 for references). 164 Aggregation resulted in 15 functional groups from primary producers to piscivorous fish and 165 cephalopods (Table 1). The trophic level (TL) of each species was estimated based on its $\delta^{15} \mathrm{~N}$ 
166 using the scaled method proposed by Hussey et al. (2014) where the trophic enrichment factor 167 (TEF) of the consumer's $\delta^{15} \mathrm{~N}$ is dependent on the $\delta^{15} \mathrm{~N}$ value of its prey:

$$
T L_{\text {consumer }}=\left(\frac{\log \left(\delta^{15} \mathrm{~N}_{\text {lim }}-\delta^{15} \mathrm{~N}_{\text {base }}\right)-\log \left(\delta^{15} \mathrm{~N}_{\text {lim }}-\delta^{15} \mathrm{~N}_{T P}\right)}{k}\right)+T L_{\text {base }}
$$

169 where $\delta^{15} \mathrm{~N}_{\text {lim }}$ is the saturating $\delta^{15} \mathrm{~N}$ limit as TL increases, $\delta^{15} \mathrm{~N}_{\text {base }}$ is the $\delta^{15} \mathrm{~N}$ value of the 170 isotopic baseline, $\delta^{15} \mathrm{~N}_{\mathrm{TP}}$ is the consumer's $\delta^{15} \mathrm{~N}$ value at a given TL, and $k$ is a rate constant 171 (Hussey et al. 2014). Values for the parameters $\delta^{15} \mathrm{~N}_{\mathrm{lim}}, \delta^{15} \mathrm{~N}_{\mathrm{TP}}$, and $k$ were taken from Hussey 172 et al. (2014). The bivalve $A$. opercularis was used as isotopic baseline $\left(\mathrm{TL}_{\mathrm{base}}=2\right)$. Trophic 173 level for each functional group was then calculated as the mean value for all individuals within 174 the group (Table 1).

175 The topological description of the food web consisted of trophic links between 176 functional groups expressed as a binary matrix. A trophic link was established if at least one 177 species of the consumer group fed on one species within the source group according to DT 178 analysis. The relative contributions of each source to consumers' diets were then estimated 179 using the Bayesian isotope mixing model IsoWeb (Kadoya et al. 2012). Isotope mixing models 180 are based on the principle that a consumer's isotopic ratios result from the mixing of the 181 isotopic ratios of its food sources according to their relative contributions to its diet after 182 accounting for TEF (Post 2002). While simple analytical mixing models can only estimate 183 contributions of a few food sources to a single consumer's diet at a time, IsoWeb has the 184 advantage of estimating dietary contributions for all consumers in a food web based on SI data 185 and a topological description of the food web given a priori. The model also allows for TEF 186 variation across links assuming that TEFs follow a normal distribution with a mean of 0.8 for 187 carbon and 3.4 for nitrogen (Post 2002, Saigo et al. 2015, Fukumori et al. 2016). The standard 
188 deviations of these normal distributions are assumed to follow a half-Cauchy distribution, for

189 both carbon and nitrogen (see details in Kadoya et al. 2012). Nitrogen TEF values estimated

190 from Hussey's equation (TL calculations) were close to those proposed in IsoWeb (mean value

191 of 3.1). Hussey's equation provides TEF estimates between prey and predator species pairs,

192 while IsoWeb estimates TEF between functional groups (several species) preventing a direct

193 comparison of the estimates obtained by the two methods. The posterior probability densities

194 of TEFs for carbon and nitrogen from this study are provided in the supplementary Figure 2S.

195 The IsoWeb model was run with the following parameters: $10^{6}$ chain length, burn-ins 500.000 ,

196 and thin number 500 for three parallel MCMC chains. Convergence was assessed using the

197 Gelman-Rubin test (Gelman et al. 2014).

198 Estimation of predatory fish diet as a function of depth

199 The resulting EEC-scale food web (referred to as IsoWeb model hereafter) was then

200 used as a template to further explore the effect of depth on food resource use by fish functional

201 groups using the Bayesian isotope mixing model MixSIAR (Stock and Semmens 2013).

202 Compared to IsoWeb, MixSIAR can incorporate continuous covariates as predictors of

203 sources' relative contributions to consumers' diet and multiplicative error structures. In this

204 study, depth was introduced as a continuous covariate affecting sources' contributions to

205 functional groups' diets. Because the model fits a continuous covariate (here depth) as a linear

206 regressor on sources contributions in Isometric Log-Ratio (ILR) transform-space (see Francis

207 et al. 2011; Egozcue and Pawlowsky-Glahn 2003 for details), it can also extrapolate changes in

208 sources' contributions to diet beyond the limits of the observed distribution of the covariate. As

209 results are presented in the space of sources' relative contributions to consumers' after

210 reciprocal transformation from the ILR transform space, depth effect may look non-linear

211 whereas it is linear in the ILR transform space. MixSIAR models were first run for each 
212 functional group keeping the same trophic links, estimated TEFs, and Bayesian model

213 parameters as the ones previously used by IsoWeb. For every MixSIAR dietary estimate, mean

214 contributions and standard deviations are reported.

215 The "Planktivorous fish" group was excluded from this analysis due to insufficient

216 sample size (40 individuals) to explore diet variation with depth as a continuous covariate.

217 Visual inspection of the final isotopic space (referred to as IsoSpace hereafter) and correlation

218 coefficients between prey sources allowed for the determination of when two sources were

219 indistinguishable. For instance, if two sources presented high overlap in their SI ratios, then,

220 likely solutions could involve one of the two sources but not both at the same time (Inger et al.

221 2010). Sources were aggregated a priori only if the absolute value of the coefficient of

222 correlation was higher than 0.5 and if the combined sources had some functional or ecological

223 significance (e.g., "Benthic decapods-omnivores" and "Benthic decapods-carnivores"

224 combined into "Benthic decapods") following suggestions by Phillips et al. (2005). Whenever

225 sources were combined, the model was re-run under the same settings (i.e., same MCMC

226 parameters). Convergence was assessed using the default MixSIAR diagnostic Gelman-Rubin

227 and Geweke tests. For each fish functional group, the plot of the IsoSpace and the mean

228 contribution of sources to the diet as a function of depth are reported. The resulting posterior

229 distributions of sources' contributions to fish functional groups' diets at the EEC-scale (i.e.

230 without accouting for the influence of depth) and at the minimum and maximum depths are

231 also provided in Supplementary Figure S3 to allow assessing uncertainty in the effect of depth

232 on functional groups' diets.

\section{Results}

234 EEC-scale food web (IsoWeb model) 
236 for benthic-suspension feeders (mainly bivalves and gastropods) to almost 5 for cephalopods.

237 Fish TLs varied from 3.17 for planktivorous to 4.4 for demersal piscivorous fish (Table 1).

238 Benthic-suspension feeders were the main food source for endobenthos-feeding fish (30\% of

239 the diet) while copepods represented the main food source (27\%) for benthos-feeding fish

240 (Table 2). Almost equal contributions of all sources to the diet of piscivorous fish (both

241 demersal and pelagic) and cephalopods suggest generalist diets for the higher TL species. The

242 combined contribution of benthic sources accounted for $54 \%$ of the diet of planktivorous fish

243 while pelagic subsidies (copepods and macro-zooplankton) represented 46\%. Likewise, benthic

244 and pelagic sources represented $51 \%$ and $49 \%$, respectively, of the diet of piscivorous pelagic

245 fish (Table 2). In contrast, the diet of benthos-feeding, endobenthos-feeding and demersal

246 piscivorous fish was largely dominated by benthic subsidies (73\%, 100\% and 100\%,

247 respectively; Table 2). Overall, the contribution of benthic subsidies (i.e., benthic OM, 248 suspension feeders, deposit feeders, benthic predators, and benthic decapods) dominated the 249 diet (51 to 100\%) of all fish functional groups, even for those that are commonly reported as 250 pelagic (e.g., planktivorous fish) (Table 2).

251 Fish diet variation with depth (MixSIAR models)

252 Using the previous model (IsoWeb) as a template (i.e., same topology and TEF factors), 253 changes in diet with depth, described as a continuous variable, were explored for each fish 254 functional group. Benthos-feeding fish ( $n=237$ individuals) were highly variable in terms of $255 \delta^{13} \mathrm{C}$ values $\left(\delta^{13} \mathrm{C}\right.$ range: $-15.45 \%$ to $-18.98 \%$ ) suggesting that different carbon sources 256 contributed to their diet. An initial MixSIAR model run with the 5 potential sources of this 257 functional group (Figure 1a) showed a large overlap between SI ratios of copepods and deposit 
258 feeders as prey (correlation of -0.90). However, these prey groups were not pooled together to 259 keep pelagic and benthic sources separate. As a result, large standard deviations (hereafter 260 referred to as SD) were observed for estimated sources' contributions to diet due to the 261 difficulty of the model to fully distinguish between the two sources. Overall diet (i.e., 262 integrated across all depths) indicated that individuals fed mainly on copepods $(36.2 \pm 22.7 \%$ 263 of their diet) and deposit feeders $(31.3 \pm 19.5 \%)$ followed by benthic decapods-omnivores prey 264 (13.5 $\pm 5.3 \%)$. Cephalopods and benthic-suspension feeders were minor dietary items 265 representing less than $10 \%$ of individuals' diet each $(8.5 \pm 4.6 \%$ and $10.5 \pm 8.3 \%$ respectively).

266 Including depth as a continuous covariate of sources' contributions showed that individuals fed 267 primarily on copepods at shallow depths $(<40 \mathrm{~m})$ and increased their consumption of deposit 268 feeders with increasing depth (Figure 1b). The contribution of other sources remained low $269(<15 \%)$ and showed little variation with depth. Posterior distributions of sources' contributions 270 (Figure S3, $1^{\text {st }}$ row) show that, despite some uncertainty in sources' contributions at the global 271 scale, there is a clear discrimination between benthic and pelagic sources as depth increases.

A first model for endobenthos-feeding fish $(n=149$ individuals $)$ showed a large 273 overlap between SI values of benthic predators and deposit feeders as sources (correlation of 274 0.78). They were combined into a common "benthic predators-worms" group leading to a 4 275 source mixing model (Figure 1c). Overall, individuals fed mainly on benthic-suspension 276 feeders $(63.8 \pm 5.0 \%)$ and benthos-feeding fish $(23.8 \pm 6.4 \%)$. The combined source "benthic 277 predators-worms" and benthic decapods-omnivores appeared as minor dietary sources $(6.2 \pm$ $2786.5 \%$ and $6.2 \pm 5.4 \%$, respectively). Including depth as a continuous covariate showed that 279 individuals fed mainly on benthic-suspension feeders from shallow waters $(7 \mathrm{~m})$ up to $60 \mathrm{~m}$ 280 depth. Their contribution decreased substantially in deeper waters (from $\sim 60 \%$ at $40 \mathrm{~m}$ depth to 
$281 \sim 10 \%$ at $80 \mathrm{~m}$ depth). The contribution of benthos-feeding fish also decreased with increasing 282 depth, whereas the contribution of "benthic predators-worms", that represented a minor source 283 in shallow waters, increased strongly with depth to become the main source in the deepest 284 waters (Figure 1d). Posterior distributions of sources' contributions (Figure S3, $2^{\text {nd }}$ row) show 285 the clear shift of main sources as depth increases.

286 Demersal piscivorous fish ( $n=133$ individuals) were also trophically linked to benthic 287 predators and deposit feeders. Again, the SI ratios of these two sources overlapped largely 288 (correlation of -0.88) and they were thus combined into a "benthic predators-worms" group. 289 Similarly, the SI values of benthic decapods-omnivores overlapped with those of benthic 290 decapods-predators and these groups were combined into a "benthic decapods" group 291 (correlation of -0.52). The same held for benthos-feeding fish and benthic decapods 292 (correlation of -0.91) but these sources were kept separate because of functional difference, 293 which resulted in large SD values for sources' contributions to diet (Figure 2a). Overall, 294 individuals consumed mainly "benthic predators/worms" (51.2 $\pm 6.4 \%)$ followed by benthos295 feeding fish $(29.2 \pm 12.8 \%)$ and "benthic decapods" $(19.7 \pm 14.9 \%)$. Little variation of diet 296 with depth was observed (Figure 2b). "Benthic predators/worms" remained the main food 297 source regardless of the depth, although its contribution decreased slightly (from $\sim 60 \%$ to 298 40\%) with increasing depth, while benthic decapods contribution increased but always 299 remained the lowest one. Posterior distributions of sources' contributions (Figure S3, $3^{\text {rd }}$ row) 300 show that besides the relative stability of the main sources, uncertainty in their contributions 301 increases with depth.

302 Pelagic piscivorous fish ( $n=106$ individuals) was the group with the highest number of 303 trophic links (7 sources), which increased uncertainty in the mixing models. As for the 
304 previous group, benthic decapods species were combined into a single source (correlation of 305 0.55). Similarly, "planktivorous fish" and "macro-zooplankton" were combined into a 306 "planktivores" group (correlation of -0.55). As a result, 5 potential sources instead of 7 were

307 considered (Figure 2c). Individuals were highly dispersed in terms of $\delta^{15} \mathrm{~N}$ values $\left(\delta^{15} \mathrm{~N}\right.$ range:

308 from $11.78 \%$ o to $18.29 \%$ ) suggesting feeding at different TLs. A large overlap in SI values was

309 still present between "planktivores" and "benthic decapods" (correlation of -0.85). However,

310 these sources were kept separate to distinguish pelagic and benthic sources. Overall,

311 individuals consumed mainly copepods $(37.6 \pm 10.2 \%)$ followed by "planktivores" $(27.21 \pm$

312 24.1\%) and "benthic decapods" (26.5 \pm 16.6\%). Benthic-suspension feeders and benthic

313 predators were minor sources representing less than $5 \%$ of the diet $(3.9 \pm 3.8 \%$ and $4.9 \pm 6.1 \%$

314 respectively). When depth was included as a continuous covariate, individuals appeared to feed

315 mainly on a mixture of copepods and "benthic decapods" in shallow waters $(\sim 7 \mathrm{~m}$ depth), but

316 their contribution progressively decreased with depth while the contribution of "planktivores"

317 increased to dominate diet in the deepest waters (Figure 2d). Posterior distributions of sources'

318 contributions (Figure S3, $4^{\text {th }}$ row) show that, despite some uncertainty in benthic decapods'

319 contribution at the global scale, there is a clear discrimination between the main food sources, 320 notably of benthc and pelagic origin, along the depth gradient.

\section{Discussion}

We present the major trophic pathways towards the main fish species of a semi-

323 enclosed sea and how they vary with depth. Species are not studied in isolation, but instead are

324 positioned within the food web and grouped into functional groups that take into account 325 several biological (taxonomy, feeding strategy, trophic guild, and morphology) and habitat 326 (pelagic, demersal) characteristics that are frequently used in trophic web studies and modeling 
327 approaches. Our results indicate high mixing of pelagic and benthic trophic pathways towards

328 fish in general over a large area $\left(35.000 \mathrm{~m}^{2}\right)$, but also highlight species' ability to forage 329 preferentially on different prey when moving from shallow to deep waters. With increasing 330 depth, benthic-pelagic and pelagic-benthic couplings weaken gradually (and almost linearly) 331 and species' diet more closely reflects their pelagic or benthic affinity (Figure 3). Some fish 332 functional groups related to the bottom, namely endobenthos-feeding fish and demersal 333 piscivorous fish, rely exclusively on benthic sources indicating some dietary specialization. In 334 contrast, benthos-feeding fish and pelagic piscivorous fish integrate both pelagic and benthic 335 sources as part of their diet depending on depth, suggesting a more opportunistic feeding 336 strategy. More precisely, the benthos-feeding group relies partly on pelagic sources at shallow 337 depth whereas they favor benthic subsidies as depth increases. Inversely, pelagic piscivorous

338 fish feed on benthic sources in shallow waters and focus more and more on pelagic subsidies as 339 depth increases. This conclusion was reached thanks to an original approach combining two 340 Bayesian modeling approach: IsoWEB and MixSIAR.

\section{Modeling considerations}

342 The combined use of two different Bayesian mixing models (IsoWeb Kadoya et al.,

3432012 \& MixSIAR Semmens et al. 2015), using DT and SI data simultaneously resulted in 344 better estimates than when used independently and compensated for some of each other's' 345 drawbacks. One of the main advantages of IsoWeb is the use of non-isotopic data, generally 346 DT or stomach contents, to identify main predator-prey relationships that are used to define the 347 general topology of the trophic network. The weaknesses of IsoWeb are the lack of visual 348 outputs to verify that the consumer's SI values lie inside the mixing polygon defined by the 349 sources' positions in the IsoSpace (created by the outer most values of the prey following TEF 
adjustments; Phillips et al. 2014) and the lack of a correlation value between prey's SI ratios to

351 determine if sources can be discriminated based on their SI signatures. In this regard, the

352 combined use of IsoWeb with MixSIAR offers several advantages. First, MixSIAR can be

353 built upon IsoWeb calculations (e.g., trophic links, TEF estimates) and provides a simple

354 visual display of the IsoSpace for each node, combining source and TEF uncertainties

355 (Semmens et al. 2015). Second, MixSIAR provides correlation values between sources that can

356 help in making the decision of aggregating prey groups when appropriate. Finally, MixSIAR

357 can include environmental (e.g., depth) or biological variables as covariates affecting sources'

358 contributions to a consumer's diet.

359 In some cases, natural variability in SI signatures and TEFs of the different sources

360 reduced the discriminative power of the mixing models and resulted in large standard

361 deviations of sources' contribution estimates (see the full posterior distributions of sources'

362 contributions to fish functional groups, Figure S3). Higher uncertainty was especially observed

363 when the mixing model was unable to distinguish between two sources based on their SI

364 values (e.g., copepods and benthic deposit feeders as sources for benthos-feeding fish

365 considered at the EEC-scale). However, for all groups, major and minor dietary sources and

366 dominance of benthic vs. pelagic sources could be identified at the EEC-scale. Interestingly,

367 variation in fish's SI ratios was partly explained by depth. This resulted in a clearer

368 discrimination between food sources and therefore more certain sources' contribution estimates

369 when depth was included as a covariate (Figure S3: middle and right panels versus left panels),

370 thus ultimately providing more relevant and ecologically significant information. Diet

371 estimates from IsoWeb were slightly different from those provided by MixSIAR, which can be

372 explained by two factors. First, IsoWeb allows variation in TEFs that results in larger SD

373 estimates. MixSIAR models were built upon IsoWeb outputs, therefore using the resulting 
374 mean TEFs and SDs calculated for every prey-consumer pair (out of the $10^{6}$ iterations). Values

375 of TEFs used in MixSIAR had therefore narrower variances resulting in narrower SDs in

376 MixSIAR dietary estimates when compared to IsoWeb. Second, prey sources were grouped in

377 MixSIAR models if they overlapped and their grouping had ecological significance (see

378 discussion below). Thus, the number of sources for each predator differed between IsoWeb and

379 MixSIAR models resulting in different dietary estimates.

380 Benthic-pelagic and pelagic-benthic couplings in shallow semi-enclosed marine ecosystems

381 Our results at the scale of the entire EEC (IsoWeb model) indicated equally important

382 dietary contributions of benthic and pelagic subsidies for two functional groups of pelagic fish,

383 namely planktivorous and pelagic piscivorous fish, whereas these groups are usually known to

384 feed primarily on zooplankton and small fishes (e.g., Olaso et al. 2005). In parallel, benthos-

385 feeding and endobenthos-feeding fish are known to feed on a variety of bottom animals, but

386 preferentially on crustaceans and polychaete worms, respectively, whereas demersal

387 piscivorous fish also forage on bottom-living fish. For these three functional groups, our results

388 are in agreement with previous studies (Cohen 1990) and confirm that most of their energy is

389 of benthic origin, representing $\sim 73 \%$ of their diet (IsoWeb).

390 Planktivorous fish are important prey for a large number of predators, including larger

391 fish, cephalopods, marine mammals and man (Mackinson and Daskalov 2007). A contribution

392 of benthic sources to their diet suggests that they could be key components of the benthic-

393 pelagic coupling by transferring benthic-derived carbon and energy towards higher trophic

394 levels in shallow semi-enclosed seas, which could potentially differentiate the structure and

395 functioning of their food webs from that of deeper open oceanic ecosystems (Pikitch et al.

396 2014). In the same vein, piscivores are characterized by generalist diets due to their mobility.

397 This includes a wide variety of prey from invertebrates to fish, of both pelagic and benthic 
origin, thereby contributing to benthic-pelagic coupling (Schindler et al. 1996). This is

399 exemplified by the large range of $\delta^{15} \mathrm{~N}$ values observed in piscivorous pelagic fish that 400 indicates high dietary plasticity and the consumption of prey from different TL.

401 Numerous studies in large temperate lakes, with similar characteristics as the EEC (e.g., 402 similar depth range, temperature, presence of benthic and pelagic invertebrates and fish) have 403 found patterns comparable to those of this study. Vander Zanden and Vadeboncoeur (2002), 404 using SI and stomach content data on 16 freshwater fish species (from both littoral and pelagic 405 habitats) showed that benthic-derived energy pathways accounted for more than $50 \%$ of total 406 fish energy intake and that this pattern is a general feature common to the large lakes of North 407 America (e.g., Lakes Superior, Michigan and Ontario). Similarly, several studies have 408 emphasized the role of predation and nutrient transfer by mobile predators in benthic-pelagic 409 coupling by showing that benthic invertebrates were the major prey source for pelagic fishes 410 (Stewart and Binkowski 1986, Schindler et al. 1996, Schindler and Scheuerell 2002). Due to 411 the proximity between pelagic and benthic compartments, shallow semi-enclosed seas and 412 large deep lakes (>20.000 $\mathrm{km}^{2}, \quad 80-100 \mathrm{~m}$ depth) share similar physical and biological 413 constraints affecting benthic-pelagic coupling. Moreover, it seems clear that in shallow non414 stratified waters, the basis of the benthic and pelagic food webs (i.e., primary producers and 415 primary consumers) are not independent and should be studied as inter-dependent and highly 416 connected units (Boero et al. 1996, Cresson et al. 2014b) to fully understand processes 417 affecting the structure and dynamics of aquatic trophic networks.

418 Variation of benthic-pelagic and pelagic-benthic couplings along the depth gradient

419 The use of depth as a continuous variable partly explained the variation in consumers' 420 isotopic ratios and helped untangling complex interactions in the EEC over a large spatial 
421 scale. In shallow waters, pelagic and benthic sources are highly connected and benefit primary

422 and secondary consumers in the two compartments, which are thus difficult to discriminate. It

423 is worth noting that strong links between zooplankton and zoobenthos from both functional

424 (energy fluxes) and structural (life cycle) perspectives (Boero et al. 1996), particularly in

425 coastal marine areas, may indicate even higher proportions of benthic-derived energy for

426 benthos-feeding and pelagic piscivorous fish. For example, the proximity of $\delta^{13} \mathrm{C}$ and $\delta^{15} \mathrm{~N}$

427 values of planktivores and benthic decapods rendered their discrimination by the mixing

428 models challenging. This observation highlights the strong connection between compartments,

429 where primary and secondary consumers (i.e., herbivores and omnivores) can have access to

430 both pelagic- and benthic-derived matter. Our results support the hypothesis of a greater

431 consumption of benthic prey by pelagic predators and of pelagic prey by benthic predators in

432 shallow waters. Our results, transposing the initial observations by Kopp et al. (2015) in a

433 depth continuum, suggest stronger benthic-pelagic and pelagic-benthic couplings with

434 decreasing depth through plasticity in fish diet, in addition to already known physical processes

435 (e.g., vertically mixed waters) and ecological features (e.g., vertical migration of zooplankton

436 and epibenthic fauna). In semi-enclosed marine ecosystems, depth is correlated with other

437 environmental and oceanographic variables (e.g., distance to shore, distribution of water

438 masses, currents) making it a suitable variable to account for habitat variation and its potential

439 effect on species diet. The gradual, almost linear, change in the strength of benthic-pelagic and

440 pelagic-benthic couplings along the depth gradient (Figure 3 ) is probably related to the fact that

441 waters are well-mixed in such ecosystems and the resulting absence of physical barrier in the

442 water column. In open oceanic ecosystems, it is likely that the strength of these couplings shifts

443 more abruptly with depth in relation to physical barriers such as thermoclines or transitions

444 between euphotic, dysphotic and aphotic zones. It is also expected that in such ecosystems 
445 other parameters than depth need to be considered to fully account for the spatial heterogeneity 446 of benthic-pelagic and pelagic-benthic couplings. For example, at a given depth, varying 447 distance to marginal ice zones in the Barents Sea has been proven to influence pelagic-benthic 448 coupling (Tamelander et al. 2006). Similarly, seasonal or inter-annual variations in surface 449 primary and secondary productions modulate the amplitude of primary carbon sources that 450 reaches the bottom and different oceanographic features (e.g., currents, eddies, water column 451 stratification) and ecological features (e.g., structure of the pelagic-food web) can be better 452 proxies than depth to account for variation in the pelagic-benthic coupling (Grebmeier and 453 Barry 1991). Finally, the role of species that perform wide diel vertical migrations (fish and 454 zooplankton) in the pelagic-benthic coupling has also been highlighted in the North Atlantic 455 and Mediterranean seas. Most of these species concentrate at the upper and mid continental 456 slope depths $(300-500 \mathrm{~m})$ making them accessible to both, benthic and bentho-pelagic feeders, 457 resulting in relatively strong coupling between benthic and pelagic production (Tecchio et al. 458 2013, Trueman et al. 2014).

459 Other sources of dietary variation

460 Apart from benthic-pelagic and pelagic-benthic couplings, a change in diet with depth 461 is expected due to the mosaic of habitats (i.e., spatial differences in prey abundance or 462 composition due to different sediment types or other abiotic conditions). Endobenthos-feeding 463 fish had no trophic link identified (from previous DT analysis; Cachera et al. 2017) with 464 pelagic prey. Their main prey were all benthic and, due to their sedentary behavior, little 465 variation in diet was expected. However, endobenthos-feeding fish diet varied largely with 466 depth. This pattern could be linked to variation in the abundance of their various benthic prey. 467 Endobenthos-feeding fish fed mainly on benthic-suspension feeders in shallow waters (e.g., $46865.5 \%$ of their diet at $25 \mathrm{~m}$ ) and switched to benthic-predators and worms in deeper waters 
469 (e.g., $76 \%$ at $75 \mathrm{~m}$ depth). Unfortunately, the benthic-suspension feeders group included 470 bivalves and gastropods that are present in both shallow and deep waters. Similarly, there is no 471 published evidence of a higher abundance of worms in deeper waters in the EEC that could 472 explain the increase of their contribution with increasing depth and no high resolution data on 473 the spatial distribution of polychaetes worms is available for the area. The absence of a known 474 spatial trend in the abundance of both prey sources prevents from being conclusive about the 475 relationship between endobenthos-feeding fish's diet change and prey spatial distribution. 476 However, similar diet variability was found in flatfishes from the Bering Sea. In this area, 477 bivalves dominated flatfishes' diet on the inner shelf (shore to $50 \mathrm{~m}$ ), while polychaetes were 478 the main prey on the middle shelf ( $\sim 50$ to $100 \mathrm{~m})$. In this case, diet changes were associated 479 with estimated trends in prey abundance (Yeung and Yang 2014). The authors however 480 emphasized the possible mismatch between diet composition and infauna abundance in regions 481 with high prey availability, where endobenthos-feeding fish preferentially feed on polychaetes 482 even when they are not the dominant prey.

483 Demersal piscivorous fish had direct trophic links with benthic sources only. Small 484 variations with depth were observed, the diet being composed of benthic predators and worms $485(\sim 40-50 \%)$ followed by bottom-living fish (i.e., Benthos-feeder fish, $\sim 31 \%$ ) and benthic 486 decapods (15-25\%). Our results suggest a more generalist diet than the other functional groups 487 with little intra- and inter-specific variability as shown by the weak dispersion of the 488 consumer's SI ratios. Previous studies have however highlighted high spatial and temporal 489 variability in the diet of species from this group (e.g., Atlantic cod, Daan 1973) that includes a 490 wide variety of prey. This discrepancy might be explained by the fact that we used SI data that 491 integrate diet over longer periods of time than stomach contents. Spatio-temporal diet 492 variability in highly mobile generalist species such as demersal piscivorous fish may integrate 
493 out in terms of SI signature and result in rather similar SI ratios that are unrelated to the

494 sampling depth. Similar patterns have been observed in shelf and lacustrine fish assemblages,

495 where higher TL species integrate coupling of pelagic and benthic pathways, resulting into

496 intermediate $\delta^{13} \mathrm{C}$ values (Woodland and Secor 2013, Schindler and Scheurell 2002). Although

497 the endobenthos-feeding and demersal piscivorous fish had trophic links with benthic prey

498 only, it is worth noting that our approach accounts only for direct predator-prey interactions

499 and that pelagic organic matter might still fuel benthic fish through indirect trophic links (i.e.,

500 contribution of pelagic organic matter to the diet of primary consumers), that would then

501 benefit indirectly from pelagic-benthic coupling.

502 Concluding remarks

503 The aim of this study was to provide information on the fundamental structure of the trophic

504 network involving fish functional groups in a semi-enclosed sea and over a large spatial scale.

505 The use of Bayesian mixing models integrating both DT and SI data indicated high connection

506 between benthic and pelagic compartments. Including depth as an environmental covariate, the

507 results showed that strong benthic-pelagic and pelagic-benthic couplings in shallow waters

508 result in fish benefiting from both benthic- and pelagic-derived matter as part of their diet. As

509 waters become deeper, these couplings weaken and species consume prey (either benthic or

510 pelagic) progressively more according to their habitat preferences. Future studies in epi-

511 continental seas should include environmental variables such as depth as proxies of habitat

512 variation to untangle consumers' resource use and highlight potentially varying energy

513 pathways structuring food webs. Results from this study enhance our comprehension of trophic

514 interactions sustaining the fish community, which is essential for management and informed

515 decision-making. 


\section{Acknowledgments}

517 The post-doctoral position of C. Giraldo was funded by the regional council "Hauts de France" 518 through the project SIMODYN (grant $\mathrm{n}^{\circ} 2014 \_10396$ ). This study is part of the CPER project

519 MARCO (grant n²016 regional council "Hauts de France" and Préfecture du Nord Pas de

520 Calais). We thank Paul Auchon for his fruitful ideas regarding this study, and Manuel

521 Rouquette and Mickael Baheux (RHBL Ifremer Boulogne sur Mer) for their valuable help in 522 the laboratory. The authors thank Dr. Tracey Loewen from Fisheries and Oceans Canada for 523 proofreading and editing and 2 anonymous reviewers for their valuable feedback that improved 524 the manuscript. 


\section{References}

527 Barnes, C., S. Jennings, and J. Barry. 2009. Environmental correlates of large-scale spatial 528 variation in the $\delta 13 \mathrm{C}$ of marine animals. Estuar. Coast. Shelf Sci. 81: 368-374.

529 Baustian, M., G. Hansen, A. de Kluijver, and K. Robinson. 2014. Linking the bottom to the top 530 in aquatic ecosystems: mechanisms and stressors of benthic-pelagic coupling. Eco-DAS X $531 \quad$ Symp. Proc. 4: 38-60.

532 Boero, F., G. Belmonte, G. Fanelli, and S. Piraino. 1996. The continuity of living matter and 533 the discontinuities of its constituents: do plankton and benthos really exist? Trends Ecol. $534 \quad$ Evol. 11: 177-180.

535 Cachera, M., B. Ernande, Ching. M. Villanueva, and S. Lefebvre. 2017. Individual diet 536 variation in a marine fish assemblage: Optimal Foraging Theory, Niche Variation 537 Hypothesis and functional identity. J. Sea Res. 120: 60-71.

538 Casini, M., M. Cardinale, and F. Arrhenius. 2004. Feeding Preferences of Herring (Clupea 539 harengus) and Sprat (Sprattus sprattus) in the Southern Baltic Sea. ICES J. Mar. Sci. 61: 1267-77. doi:10.1016/j.icesjms.2003.12.011

541 Cohen, D. M. 1990. Gadiform Fishes of the World (Order Gadiformes): An annotated and 542 illustrated catalogue of cods, hakes, grenadiers, and other gadiform fishes known to date. $543 \quad$ FAO species catalogue, Vol 10, p. 442.

544 Cresson, P., M.C. Fabri, M. Bouchoucha, and others. 2014a. Hg in organisms from the 545 Northwestern Mediterranean slope: importance of the food sources. Sci. Total Environ. 546 497-498, 229-238. http://dx.doi.org/10.1016/j.scitotenv.2014.07.069. 
547 Cresson, P., S. Ruitton, and M. Harmelin-Vivien M. 2014b. Artificial reefs do increase

548 secondary biomass production: mechanisms evidenced by stable isotopes. Mar Ecol Progr

$549 \quad$ Ser 509:15-26. http://dx.doi.org/10.3354/meps.10866

550 Daan, N. 1973. A Quantitative Analysis of the Food Intake of North Sea Cod, Gadus Morhua.

$551 \quad$ Neth J. Sea Res. 6: 479-517. doi:10.1016/0077-7579(73)90002-1

552 Egozcue, J., and V. Pawlowsky-Glahn. 2003. Isometric Logratio Transformations for 553 compositional data analysis. Math. Geol. 35: 279-300.

554 Foucher, E., J. Quinquis. 2010. COMOR 40 cruise, RV Thalia.

555 http://dx.doi.org/10.17600/10070120

556 Francis, T. B., D. E. Schindler, G. W. Holtgrieve, and others. 2011. Habitat structure

557 determines resource use by zooplankton in temperate lakes. Ecol. Lett. 14: 364-72.

$558 \quad$ doi:10.1111/j.1461-0248.2011.01597.x

559 Fukumori, K., E. Yoshizaki, N. Takamura, and T. Kadoya. 2016. Detritivore diversity

560 promotes a relative contribution rate of detritus to the diet of predators in ponds.

$561 \quad$ Ecosphere 7(3). doi:10.1002/ecs2.1211

562 Gaudron, S. M., K. Grangeré, and S. Lefebvre. 2016. The comparison of $\delta 13 \mathrm{C}$ values of a

563 deposit- and a suspension-feeder bio-indicates benthic vs. pelagic couplings and trophic

564 status in contrasted coastal ecosystems. Estuaries Coasts 39: 731-41. doi:10.1007/s12237-

$565 \quad 015-0020-x$

566 Gelman, A., J. Carlin, H. Stern, and D. Rubin. 2014. Bayesian Data Analysis. Vol 2, Boca

567 Raton, FL, USA: Chapman \& Hall/CRC. 
568 Gibson, R., R. Nash, A. Geffen, and H. Van der Veer. 2014. Flatfishes: Biology and $569 \quad$ Exploitation. John Wiley \& Sons.

570 Grebmeier, J. M. 1993. Studies of pelagic-benthic coupling extended onto the soviet

571 continental shelf in the Northern Bering and Chukchi Seas. Cont. Shelf Res. 13: 653-68. 572 doi:10.1016/0278-4343(93)90098-I

573 Grebmeier, J. M., and J. P. Barry. 1991. The influence of oceanographic processes on pelagic574 benthic coupling in polar regions: A benthic perspective. J. Mar. Syst. 2: 495-518. 575 doi:10.1016/0924-7963(91)90049-Z

576 Hussey, N. E., M. A. Macneil, B. C. McMeans, and others. 2014. Rescaling the trophic 577 structure of marine food webs. Ecol. Lett. 17: 239-50. doi:10.1111/ele.12226

578 Iken, K., T. Brey, U. Wand, J. Voigt, and P. Junghans. 2001. Food web structure of the benthic 579 community at the porcupine abyssal plain (NE Atlantic): A stable isotope analysis. Prog. $580 \quad$ Oceanogr. 50: 383-405. doi:10.1016/S0079-6611(01)00062-3

581 Inger, R., A. Jackson, A. Parnell, and S. Bearhop. 2010. SIAR v4 (Stable Isotope Analysis in $582 \quad$ R): An Ecologist's Guide.

583 Ings, T. C., J. M. Montoya, J. Bascompte, and others. 2009. Ecological Networks--beyond 584 Food Webs. J. Anim. Ecol. 78: 253-69. doi:10.1111/j.1365-2656.2008.01460.x

585 Jennings, S., and K.J. Warr. 2003a. Environmental correlates of large-scale spatial variation in 586 the $\delta 15 \mathrm{~N}$ of marine animals. Mar. Biol. 142: 1131-1140.

587 Jennings, S., and K. K. J. Warr. 2003b. Smaller predator-prey body size ratios in longer food 588 chains. P. Roy. Soc. London B Bio. 270: 1413-1417. 
Juanes, F., J. Buckel, and F. Scharf. 2002. Feeding ecology of piscivorous fishes. Handbook of fish biology and fisheries, Vol 1: Fish biology p. 267-283.

Jönsson, M., L. Ranåker, P. A. Nilsson, C, Brönmark. 2013. Foraging efficiency and prey selectivity in a visual predator: differential effects of turbid and humic water. Can. J. Fish Aquat. Sci. 70: 1685-1690.

Kadoya, T., Y. Osada, and G. Takimoto. 2012. IsoWeb: A bayesian isotope mixing model for diet analysis of the whole food web. PLoS ONE 7: e41057. doi:10.1371/journal.pone.0041057

Keyl, F., and M. Wolff. 2008. Environmental variability and fisheries: What can models do? Rev. Fish Biol. Fish 18: 273-299. doi:10.1007/s11160-007-9075-5

Kopp, D., S. Lefebvre, M. Cachera, and others. 2015. Reorganization of a marine trophic network along an inshore-offshore gradient due to stronger pelagic-benthic coupling in coastal areas. Prog. Oceanogr. 130: 157-171.

Le Loc'h, F., C. Hily, and J. Grall. 2008. Benthic community and food web structure on the continental shelf of the bay of biscay (North Eastern Atlantic) revealed by stable isotopes

Le Roy, D. 2009. CGFS2009 cruise, RV Gwen Drez, http://dx.doi.org/10.17600/9050090

Link, J., K. Bolles, and C. Milliken. 2002. The Feeding Ecology of Flatfish in the Northwest analysis. J. Mar. Syst. 72: 17-34. doi:10.1016/j.jmarsys.2007.05.011 
611 Mackenzie, B. R., H. Gislason, C. Möllmann, and F. W. Köster. 2007. Impact of 21st Century

612 climate change on the Baltic Sea fish community and fisheries. Glob. Chang. Biol. 13:

$613 \quad$ 1348-67. doi:10.1111/j.1365-2486.2007.01369.x

614 Martin, C. S., A. Carpentier, S. Vaz, and others. 2010. The channel habitat atlas for marine 615 resource management (CHARM): An aid for planning and decision-making in an area 616 under strong anthropogenic pressure. Aquat. Living Resour. 22: 499-508. 617 doi:10.1051/alr/2009051

618 Mollmann, C., G. Kornilovs, M. Fetter, and F. W. Koster. 2004. Feeding ecology of central 619 Baltic Sea herring and sprat. J. Fish Biol. 65: 1563-1581. doi:10.1111/j.0022-

$620 \quad 1112.2004 .00566 . x$

621 Olaso, I., J. L. Gutiérrez, B. Villamor, P. Carrera, L. Valdés, and P. Abaunza. 2005. Seasonal 622 changes in the north-eastern Atlantic mackerel diet (Scomber scombrus) in the north of 623 Spain (ICES Division VIIIc). J. Mar. Biol. Assoc. UK 85: 415-418.

624 doi:10.1017/S0025315405011343h

625 Orlov, A. M. 1998. The diets and feeding habits of some deep-water benthic skates (Rajidae) in 626 the Pacific waters off the Northern Kuril Islands and Southeastern Kamchatka. Alaska $627 \quad$ Fish. Res. Bul. 5: 1-17.

628 Phillips, D. L., R. Inger, S. Bearhop, A. L. Jackson, J. W. Moore, A. C. Parnell, B. X. 629 Semmens, and E. J. Ward. 2014. Best practices for use of stable isotope mixing models in 630 food-web studies. Can. J. Zool. 92: 823-835. dx.doi.org/10.1139/cjz-2014-0127

631 Phillips, D., S. Newsome, and J. Gregg. 2005. Combining sources in stable isotope mixing 
models: Alternative Methods. Oecologia 144: 520-527.

633 Pikitch, E. K., K. J. Rountos, T. E. Essington, and others. 2014. The global contribution of 634 forage fish to marine fisheries and ecosystems. Fish Fish. 15: 43-64.

635 doi:10.1111/faf.12004

636 Post, D.M. 2002. Using stable isotopes to estimate trophic position: models, methods, and 637 assumptions. Ecology 83: 703-18.

638 Post, D. M., M. Conners, and D. Goldberg. 2000. Prey preference by a top predator and the 639 stability of linked food chains. Ecology 81: 8-14.

Post, D. M. D., C. A. C. Layman, D. A. DA Arrington, G. Takimoto, J. Quattrochi, and C. G.

641 Montaña. 2007. Getting to the fat of the matter: models, methods and assumptions for 642 dealing with lipids in stable isotope analyses. Oecologia 152: 179-189. doi:10.1007/s00442-006-0630-X

Romero-Romero, S., A. Molina-Ramírez, J. Höfer, and J. L. Acuña. 2016. Body size-based trophic structure of a deep marine ecosystem. Ecology. 97: 171-181.

Saigo, M., F. L. Zilli, M. R. Marchese, and D. Demonte. 2015. Trophic level, food chain length and omnivory in the Paraná River: a food web model approach in a floodplain river system. Ecol. Res. 30: 843-852. doi:10.1007/s11284-015-1283-1

Schindler, D., S. Carpenter, K. Cottingham, and X. He. 1996. Food web structure and littoral zone coupling to pelagic trophic cascades. In Food Webs p. 96-105.

651 Schindler, D. E., and M. D. Scheuerell. 2002. Habitat coupling in lake ecosystems. Oikos 98: 
653 Semmens, B., C. Brian, E. Ward, and J. Moore. 2015. MixSIAR: A Bayesian stable isotope

654 mixing model for characterizing intrapopulation niche variation.

655 https://github.com/brianstock/MixSIAR/

656 Stewart, D. J., and F. P. Binkowski. 1986. Dynamics of Consumption and Food Conversion by

657 Lake Michigan Alewives: An Energetics-Modeling Synthesis. Trans. Am. Fish. Soc. 115:

$658 \quad 643-661$.

659 Stock, B. C., B. X. Semmens. 2013. MixSIAR GUI user manual, version 1.0. Accessible

660 online at: https://github.com/brianstock/MixSIAR/releases

661 Stouffer, D. B., J. Camacho, W. Jiang, and others. 2007. Evidence for the existence of a robust

662 pattern of prey selection in food webs. Proc. Biol. Sci. 274: 1931-40.

663 doi:10.1098/rspb.2007.0571

664 Tamelander, T., P. Renaud, H. Hop, M. Carroll, J. Ambrose WG, and K. Hobson. 2006.

665 Trophic relationships and pelagic-benthic coupling during summer in the Barents Sea

666 Marginal Ice Zone, revealed by stable carbon and nitrogen isotope measurements. Mar.

667 Ecol. Prog. Ser. 310: 33-46. doi:10.3354/meps310033

668 Tecchio, S., D. van Oevelen, K. Soetaert, J. Navarro, E. Ramirez-Llodra. 2013. Trophic

669 dynamics of deep-sea megabenthos are mediated by surface productivity. PLoS ONE

670 8(5): e63796. doi:10.1371/journal.pone.0063796

671 Tecchio, S., A. Rius, J. Dauvin, and J. Lobry. 2015. The mosaic of habitats of the seine

672 estuary: insights from food-web modelling and network analysis. Ecol. Modell. 312: 91-

673101.

674 Thompson, R., U. Brose, J. Dunne, and R. Hall. 2012. Food webs: reconciling the structure and 
675 function of biodiversity. Trends Ecol. Evol 27: 689-697.

676 Trueman, C. N., G. Johnston, B. O’Hea, K. M. MacKenzie. 2014 Trophic interactions of fish

677 communities at midwater depths enhance long-term carbon storage and benthic

678 production on continental slopes. Proc. R. Soc. B 281: 20140669.

$679 \quad$ http://dx.doi.org/10.1098/rspb.2014.0669

680 Verin, Y. 2010. IBTS 2010 cruise, RV Thalassa, http://dx.doi.org/10.17600/10040010

681 Woodland, R. J., and D. H. Secor. 2013. Benthic-pelagic coupling in a temperate inner

682 continental shelf fish assemblage. Limnol. Oceanogr. 58: 966-976.

683 doi:10.4319/lo.2013.58.3.0966

684 Woodward, G., J. Benstead, and O. Beveridge. 2010. Ecological networks in a changing

685 climate. Adv. Ecol. Res. 42: 71-138.

686 Yeung, C., and M.-S. Yang. 2014. Habitat and infauna prey availability for flatfishes in the

687 northern Bering Sea. Polar Biol. 37: 1769-1784. doi:10.1007/s00300-014-1560-4

688 Yoon, I., S. Yoon, N. Martinez, and R. Williams. 2005. Interactive 3D Visualization of Highly

689 Connected Ecological Networks on the WWW. In Proceedings of the 2005 ACM

$690 \quad$ symposium on Applied computing. p. 1207-1212.

691 Vander Zanden, M.J., and Y. Vadeboncoeur. 2002. Fishes as integrators of benthic and pelagic

692 food webs in lakes. Ecology 83: 2152-2161. 


\section{Figure legends}

694 Figure 1: Diet composition of benthos-feeding (a, b) and endobenthos-feeding fish (c, d) as estimated

695 by the MixSIAR mixing model. Iso-Space (a, c) displaying consumer's individual SI values (individual

696 fish black dots) together with sources average SI values (e.g., "Copepods"; colored dots). The latter

697 have been adjusted by TEF means and are associated with error bars indicating \pm 1 standard deviation

698 resulting from combined source and discrimination (TEF) uncertainty. Variation in diet as a function of

699 depth is illustrated in panels (b, d). Sampling depth range is illustrated by the grey box and spans from

$7007-12 \mathrm{~m}$ to $80 \mathrm{~m}$. Extrapolations beyond this depth range were kept for illustration purposes. Figure 2

701 follows the same conventions as this figure.

702 Figure 2: Diet composition of demersal $(a, b)$ and pelagic piscivorous fish $(c, d)$ as estimated by the

703 MixSIAR mixing model. Iso-Space (a, c). Variation in diet as a function of depth (b, d).

704 Figure 3: Variation of the proportional benthic contribution (all benthic sources summed) to the diet of

705 fish functional groups (proportional pelagic contribution is simply obtained as 1-benthic contribution).

706 Blue dashed line: pelagic piscivorous fish; orange dash-dot line: benthos-feeding fish; red continuous

707 line: demersal piscivorous and endobenthos-feeding fish 
(a)

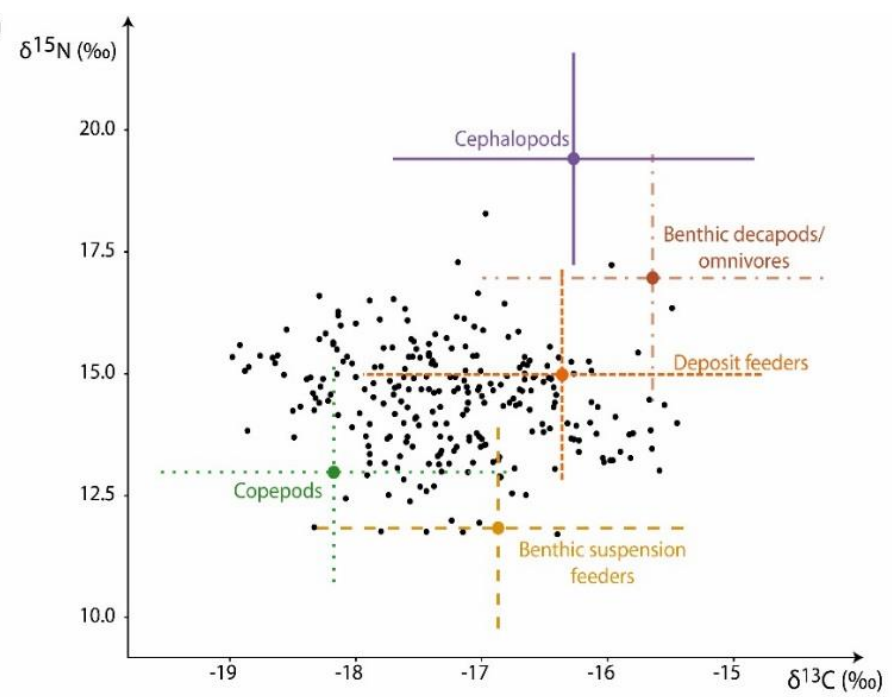

(c)

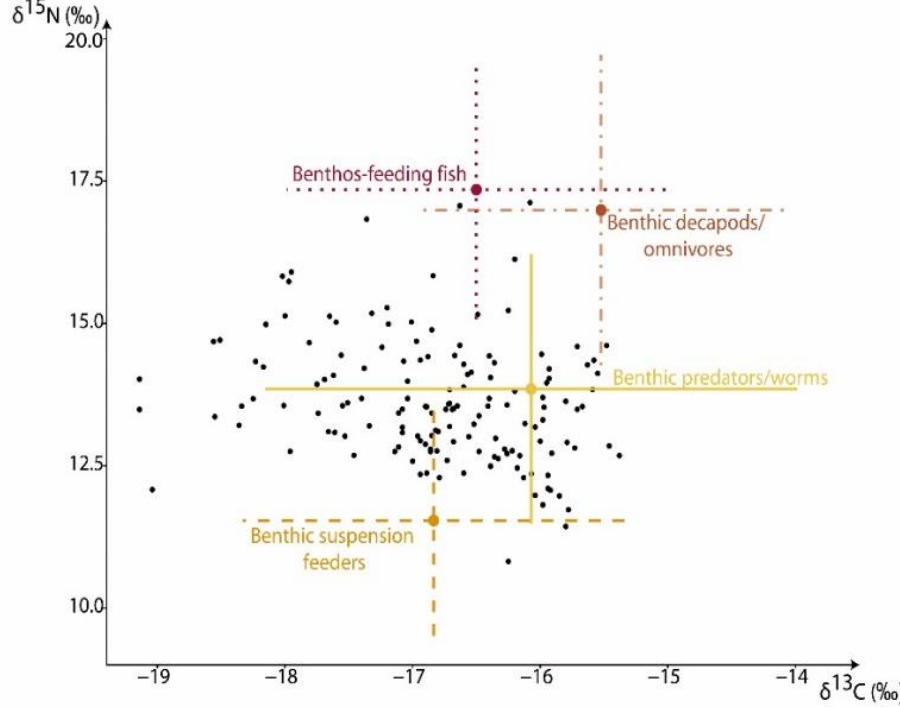

(b)

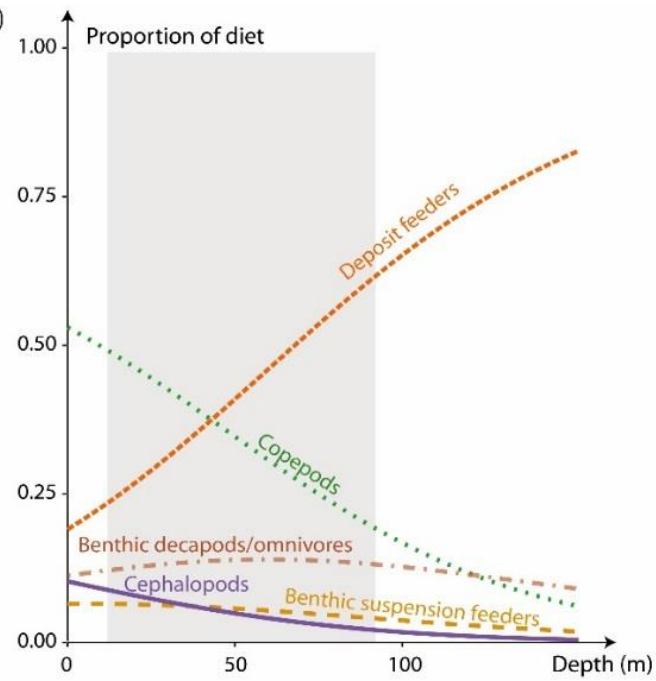

(d)

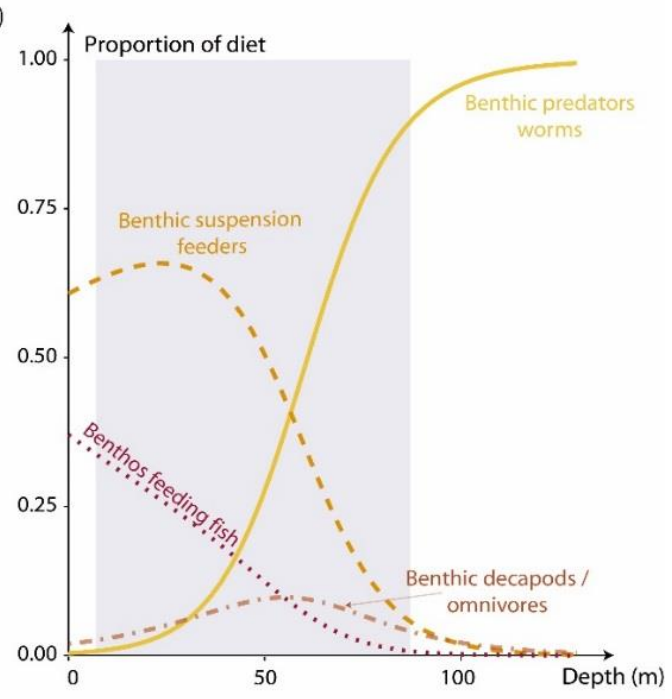




\section{$711 \quad$ Figure 2}

(a)
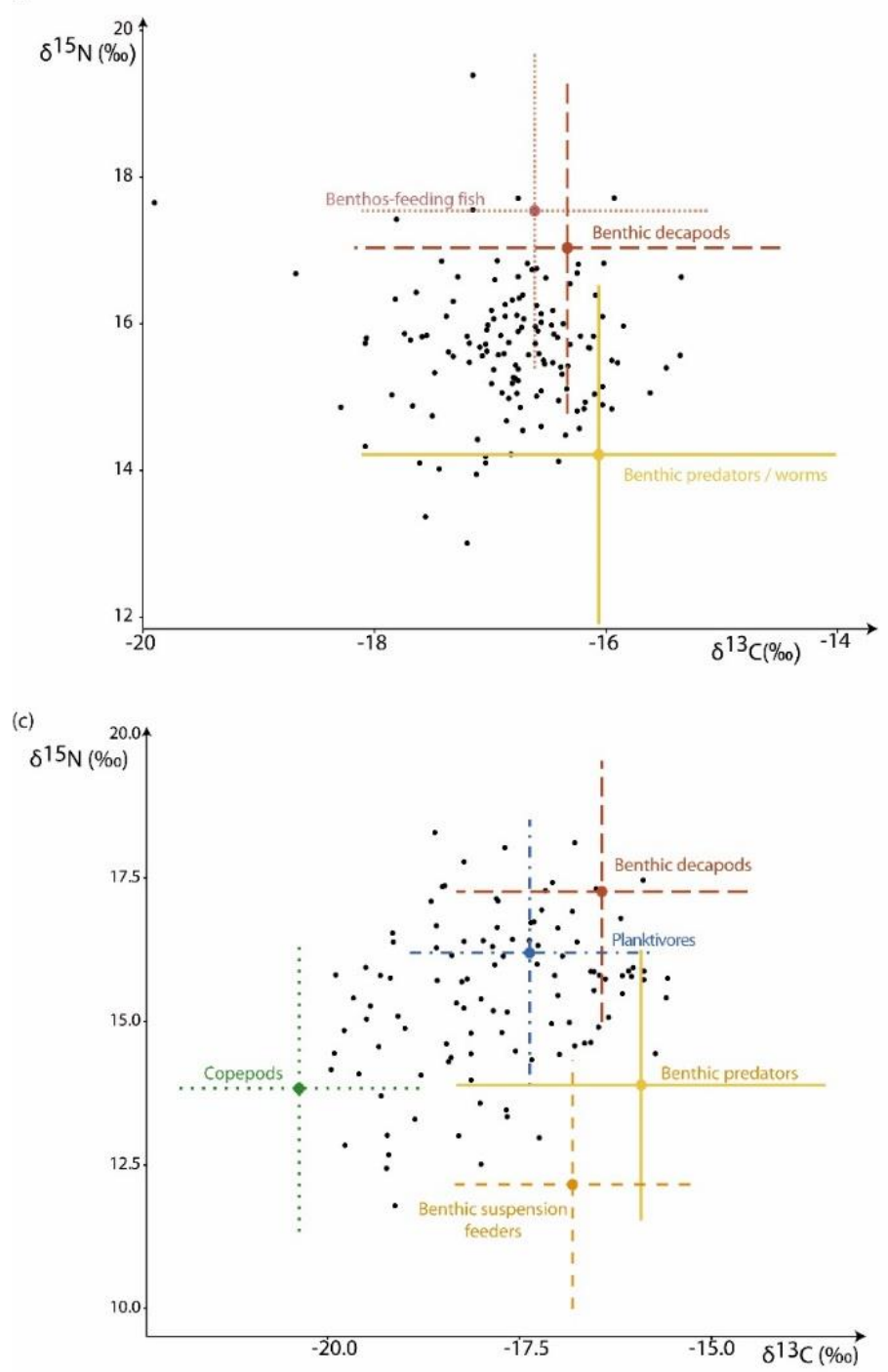

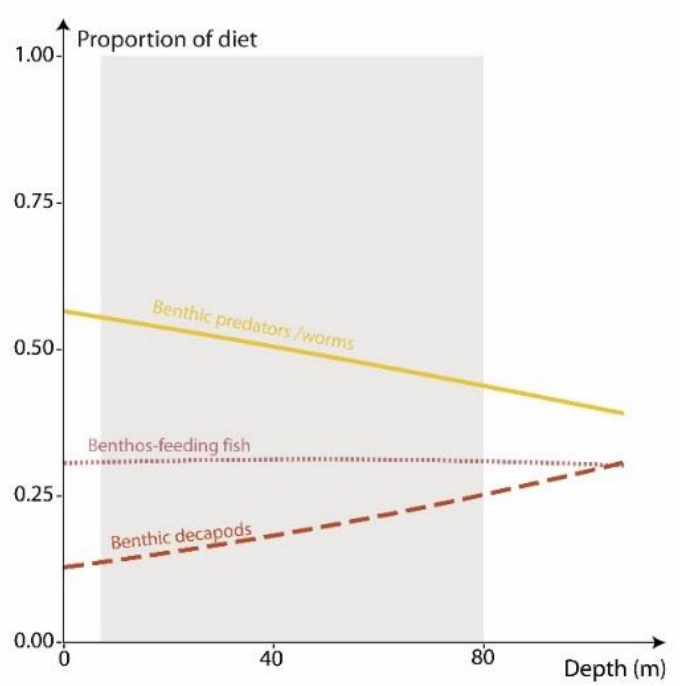

(d)

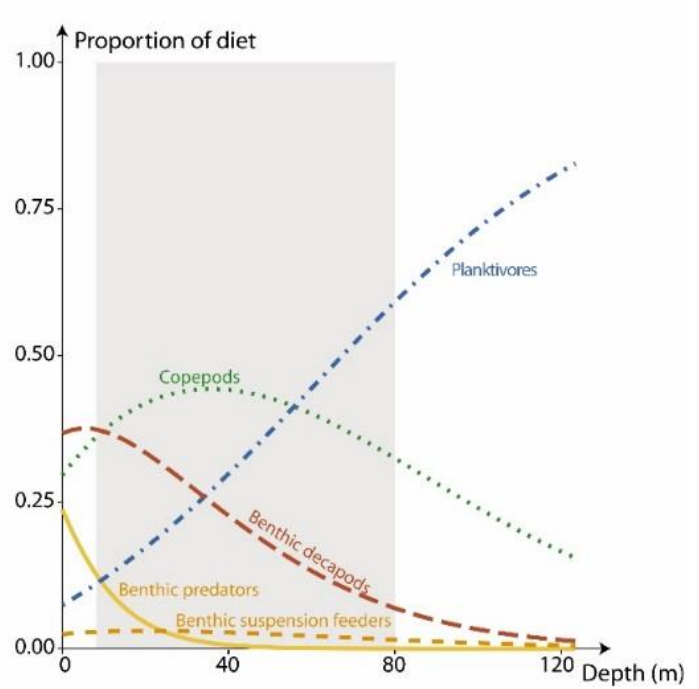


Figure 3

715

716

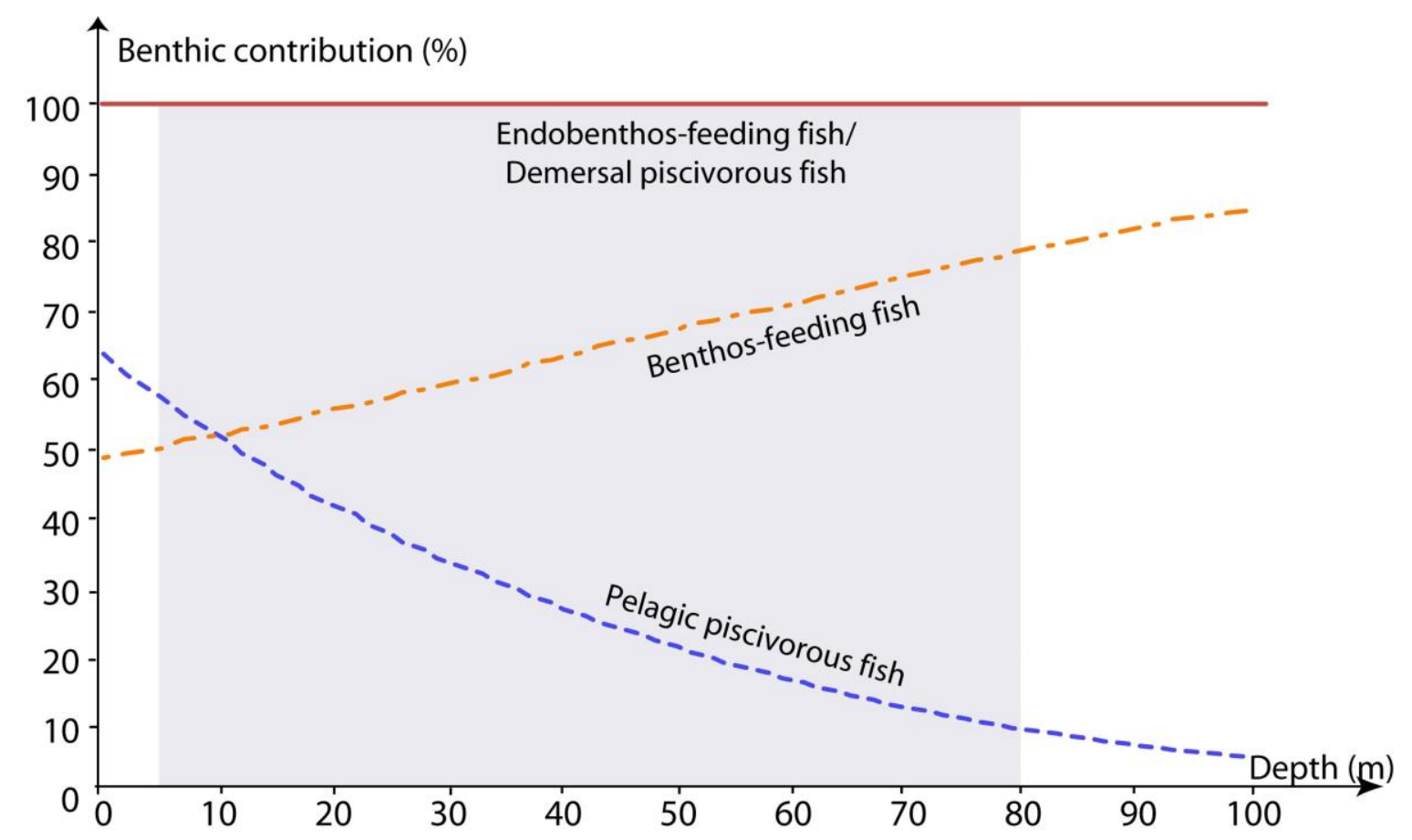

717 


\begin{tabular}{|c|c|c|c|}
\hline Functional group & Composition & Reported diet & TL \\
\hline 1. Phytoplankton & POM & - & 1 \\
\hline $\begin{array}{l}\text { 2. Benthic OM and } \\
\text { detritus }\end{array}$ & BOM & - & 1 \\
\hline 3. Copepods & Copepods & $\begin{array}{l}\text { Mostly herbivore, although some species are } \\
\text { omnivorous/carnivorous or parasites }\end{array}$ & $2.29 \pm 0.32$ \\
\hline 4. Macro-zooplankton & Chaetognaths and fish larvae & Feed on copepods and other zooplankton & $3.19 \pm 0.03$ \\
\hline $\begin{array}{l}\text { 5. Benthic-suspension } \\
\text { feeders }\end{array}$ & $\begin{array}{l}\text { Mainly bivalves and gastropods: Aequipecten } \\
\text { opercularis, Glycymeris glycymeris, } \\
\text { Laevicardium crassum, Mimachlamys varia, } \\
\text { Pecten maximus, Crepidula fornicata }\end{array}$ & $\begin{array}{l}\text { Suspension-feeder, deposit-feeeder } \\
\text { detrivore, planktivore, bacteria }\end{array}$ & $2.01 \pm 0.26$ \\
\hline 6. Deposit feeders & $\begin{array}{l}\text { Mostly Nereis sp (this study) and Aponuphis } \\
\text { tubicola, Nephtys caeca, Dasybranchus gajolae, } \\
\text { Glycera rouxii (Le Loc'h, Hily, and Grall 2008). }\end{array}$ & $\begin{array}{l}\text { Omnivores feeding on phytoplankton, } \\
\text { zooplankton, crustaceans and other worms }\end{array}$ & $2.72 \pm 0.15$ \\
\hline $\begin{array}{l}\text { 7. Benthic decapods/ } \\
\text { omnivores }\end{array}$ & $\begin{array}{l}\text { Shrimps Palaemon serratus, Processa sp. and } \\
\text { Hermit crabs Pagurus bernhardus }\end{array}$ & $\begin{array}{l}\text { Omnivores feeding on algae, crustaceans, } \\
\text { gastropods and polychaetes }\end{array}$ & $3.71 \pm 0.79$ \\
\hline $\begin{array}{l}\text { 8. Benthic decapods / } \\
\text { predators/scavengers }\end{array}$ & $\begin{array}{l}\text { Shrimp Crangon crangon and crabs Liocarcinus } \\
\text { holsatus, Maja brachydactyla, Necora puber }\end{array}$ & $\begin{array}{l}\text { Carnivores/scavengers feeding on } \\
\text { echinoderms, crustaceans, marine worms, } \\
\text { molluscs and dead fishes }\end{array}$ & $3.56 \pm 0.39$ \\
\hline 9. Benthic predators & $\begin{array}{l}\text { Mainly echinoderms Psammechinus miliaris and } \\
\text { the gastropod Buccinum undatum }\end{array}$ & $\begin{array}{l}\text { Omnivores/scavengers feeding on marine } \\
\text { worms, hydroids, small crustaceans, } \\
\text { molluscs, diatoms, macroalgae and detritus }\end{array}$ & $2.42 \pm 0.37$ \\
\hline $\begin{array}{l}\text { 10. Benthos-feeding } \\
\text { fish }\end{array}$ & $\begin{array}{l}\text { Rays Raja clavata, Gobiidae, Triglidae } \\
\text { Trigloporus lastoviza, Chelidonichthys lucerna, }\end{array}$ & $\begin{array}{l}\text { Feed on all kinds of bottom animals, } \\
\text { preferably crustaceans }\end{array}$ & $3.83 \pm 0.48$ \\
\hline
\end{tabular}




\begin{tabular}{|c|c|c|c|}
\hline & $\begin{array}{l}\text { small sharks Scyliorhinus canicula, Scyliorhinus } \\
\text { stellaris, Mustelus sp., and small fish } \\
\text { Spondyliosoma cantharus, Trisopterus luscus, } \\
\text { Trisopterus minutus, Mullus surmuletus, } \\
\text { Callionymus lyra, Eutrigla gurnardus }\end{array}$ & & \\
\hline $\begin{array}{l}\text { 11. Endobenthos- } \\
\text { feeding fish }\end{array}$ & $\begin{array}{l}\text { Flat fishes Buglossidium luteum, Limanda } \\
\text { limanda, Microstomus kitt, Platichthys flesus, } \\
\text { Pleuronectes platessa, Solea solea }\end{array}$ & $\begin{array}{l}\text { Feed on a wide range of small bottom-living } \\
\text { organisms, mainly crustaceans (amphipods, } \\
\text { shrimps), also polychaeta worms and } \\
\text { bivalve mollusks }\end{array}$ & $3.50 \pm 0.44$ \\
\hline $\begin{array}{l}\text { 12. Demersal } \\
\text { piscivorous fish }\end{array}$ & $\begin{array}{l}\text { Dicentrarchus labrax, Gadus morhua, } \\
\text { Hyperoplus lanceolatus, Merlangius merlangus, } \\
\text { Scophthalmus rhombus (flatfish feeding } \\
\text { preferentially on fish) }\end{array}$ & Feeds on fishes and larger crustaceans & $4.40 \pm 0.49$ \\
\hline 13. Planktivorous fish & $\begin{array}{l}\text { Clupea harengus, Micromesistius poutassou, } \\
\text { Sardina pilchardus, Sprattus sprattus }\end{array}$ & Feeds on planktonic crustaceans & $3.17 \pm 0.55$ \\
\hline $\begin{array}{l}\text { 14. Pelagic } \\
\text { piscivorous fish }\end{array}$ & $\begin{array}{l}\text { Zeus faber, Scomber scombrus, Trachurus } \\
\text { trachurus }\end{array}$ & Feeds on zooplankton and small fish & $4.32 \pm 0.66$ \\
\hline 15. Cephalopods & $\begin{array}{l}\text { Alloteuthis subulata, Loligo vulgaris, Sepia } \\
\text { officinalis }\end{array}$ & $\begin{array}{l}\text { Feed on a wide variety of animals, mainly } \\
\text { bony fishes and crustaceans }\end{array}$ & $4.75 \pm 0.48$ \\
\hline
\end{tabular}


722 are expressed as mean proportions with standard deviations between square brackets. (*) POM. (**) Benthic organic matter. $\sum$ B and P correspond to the sum of mean contributions of benthic $(B)$ and pelagic $(P)$ subsidies respectively.

\begin{tabular}{|c|c|c|c|c|c|c|c|c|c|c|c|c|c|c|c|c|}
\hline & \multicolumn{13}{|c|}{ Prey } & \multirow[b]{2}{*}{$\Sigma B$} & \multirow[b]{2}{*}{$\Sigma P$} & \multirow[b]{2}{*}{ Total } \\
\hline Consumer & POM & BOM & $\begin{array}{l}\frac{n}{0} \\
0 \\
\frac{0}{0} \\
0 \\
0\end{array}$ & 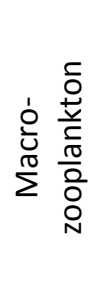 & 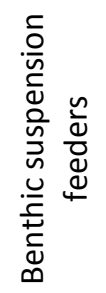 & 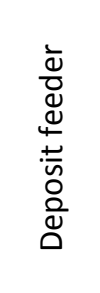 & 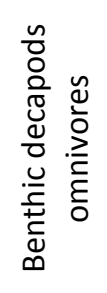 & 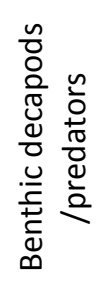 & 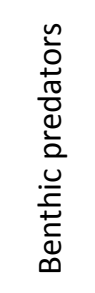 & 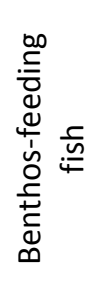 & 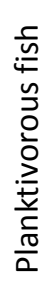 & 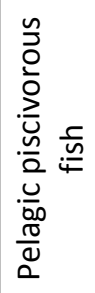 & $\begin{array}{l}\frac{n}{0} \\
0 \\
\frac{0}{0} \\
\frac{0}{\pi} \\
\frac{0}{2} \\
\frac{0}{0}\end{array}$ & & & \\
\hline Copepods & 1 & - & & - & - & & & & & & & & & - & 1 & 1 \\
\hline Macro-zooplankton & $\begin{array}{c}0.37 \\
{[0.21]}\end{array}$ & - & $\begin{array}{c}0.63 \\
{[0.21]}\end{array}$ & - & - & - & - & - & - & - & - & - & - & - & 1 & 1 \\
\hline $\begin{array}{r}\text { Benthic-suspension } \\
\text { feeders }\end{array}$ & $\begin{array}{c}0.35 \\
{[0.21]}\end{array}$ & $\begin{array}{c}0.65 \\
{[0.21]}\end{array}$ & - & - & - & - & - & - & - & - & - & - & - & 0.65 & 0.35 & 1 \\
\hline Deposit feeder & $\begin{array}{c}0.37 \\
{[0.23]}\end{array}$ & $\begin{array}{c}0.63 \\
{[0.23]}\end{array}$ & - & - & - & - & - & - & - & - & - & - & - & 0.63 & 0.37 & 1 \\
\hline $\begin{array}{r}\text { Benthic decapods } \\
\text { /omnivores }\end{array}$ & $\begin{array}{c}0.11 \\
{[0.09]}\end{array}$ & $\begin{array}{c}0.17 \\
{[0.14]}\end{array}$ & - & - & $\begin{array}{c}0.28 \\
{[0.21]}\end{array}$ & $\begin{array}{c}0.44 \\
{[0.20]}\end{array}$ & - & - & - & - & - & - & - & 0.89 & 0.11 & 1 \\
\hline $\begin{array}{r}\text { Benthic decapods } \\
/ \text { predators }\end{array}$ & - & $\begin{array}{c}0.18 \\
{[0.13]}\end{array}$ & - & - & $\begin{array}{c}0.23 \\
{[0.17]}\end{array}$ & $\begin{array}{c}0.23 \\
{[0.17]}\end{array}$ & $\begin{array}{c}0.17 \\
{[0.12]}\end{array}$ & - & $\begin{array}{c}0.19 \\
{[0.16]}\end{array}$ & - & - & - & - & 1 & - & 1 \\
\hline Benthic predators & - & - & - & - & $\begin{array}{c}0.72 \\
{[0.24]}\end{array}$ & $\begin{array}{c}0.28 \\
{[0.24]}\end{array}$ & - & - & - & - & - & - & - & 1 & - & 1 \\
\hline Benthos-feeding fish & - & - & $\begin{array}{c}0.27 \\
{[0.17]}\end{array}$ & - & $\begin{array}{c}0.24 \\
{[0.16]}\end{array}$ & $\begin{array}{c}0.21 \\
{[0.16]}\end{array}$ & $\begin{array}{c}0.15 \\
{[0.12]}\end{array}$ & - & - & - & - & - & $\begin{array}{c}0.13 \\
{[0.10]}\end{array}$ & 0.73 & 0.27 & 1 \\
\hline $\begin{array}{r}\text { Endobenthos-feeding } \\
\text { fish }\end{array}$ & - & - & - & - & $\begin{array}{c}0.30 \\
{[0.18]}\end{array}$ & $\begin{array}{c}0.20 \\
{[0.16]}\end{array}$ & $\begin{array}{c}0.14 \\
{[0.12]}\end{array}$ & - & $\begin{array}{c}0.22 \\
{[0.17]}\end{array}$ & $\begin{array}{c}0.14 \\
{[0.11]}\end{array}$ & - & - & - & 1 & - & 1 \\
\hline $\begin{array}{r}\text { Demersal piscivorous } \\
\text { fish }\end{array}$ & - & - & - & - & - & $\begin{array}{c}0.21 \\
{[0.16]}\end{array}$ & $\begin{array}{c}0.18 \\
{[0.14]}\end{array}$ & $\begin{array}{c}0.21 \\
{[0.15]}\end{array}$ & $\begin{array}{c}0.21 \\
{[0.15]}\end{array}$ & $\begin{array}{c}0.19 \\
{[0.15]}\end{array}$ & - & - & - & 1 & - & 1 \\
\hline
\end{tabular}




\begin{tabular}{|c|c|c|c|c|c|c|c|c|c|c|c|c|c|c|c|c|}
\hline Planktivorous fish & - & - & $\begin{array}{c}0.30 \\
{[0.19]}\end{array}$ & $\begin{array}{c}0.16 \\
{[0.1} \\
4]\end{array}$ & $\begin{array}{c}0.32 \\
{[0.19]}\end{array}$ & - & $\begin{array}{c}0.10 \\
{[0.09]}\end{array}$ & $\begin{array}{c}0.12 \\
{[0.11]}\end{array}$ & - & - & - & - & - & 0.54 & 0.46 & 1 \\
\hline Pelagic piscivorous fish & - & - & $\begin{array}{c}0.16 \\
{[0.12]}\end{array}$ & $\begin{array}{c}0.17 \\
{[0.1} \\
3]\end{array}$ & $\begin{array}{c}0.12 \\
{[0.10]}\end{array}$ & - & $\begin{array}{c}0.12 \\
{[0.10]}\end{array}$ & $\begin{array}{c}0.15 \\
{[0.12]}\end{array}$ & $\begin{array}{c}0.12 \\
{[0.10]}\end{array}$ & - & $\begin{array}{c}0.16 \\
{[0.1} \\
2]\end{array}$ & - & - & 0.51 & 0.49 & 1 \\
\hline Cephalopods & - & - & - & - & - & - & $\begin{array}{c}0.19 \\
{[0.15]}\end{array}$ & $\begin{array}{c}0.21 \\
{[0.16]}\end{array}$ & - & $\begin{array}{c}0.19 \\
{[0.15]}\end{array}$ & $\begin{array}{c}0.23 \\
{[0.1} \\
7]\end{array}$ & $\begin{array}{c}0.18 \\
{[0.1} \\
4]\end{array}$ & - & 0.82 & 0.18 & 1 \\
\hline
\end{tabular}

